\title{
The Seropositivity Rate of Human Herpesvirus Type 6 among Infants in Diyala Province, Iraq
}

\author{
A. Sh. Hasan, Sh. Mehdi, A. Hasan Noor \\ College of Medicine, Diyala University, Diyala, Iraq \\ Email: razak1957@yahoo.com
}

How to cite this paper: Hasan, A.Sh., Mehdi, Sh. and Noor, A.H. (2019) The Seropositivity Rate of Human Herpesvirus Type 6 among Infants in Diyala Province, Iraq. Journal of Biosciences and Medicines, 7, 129-137.

https://doi.org/10.4236/jbm.2019.76008

Received: March 23, 2019

Accepted: June 16, 2019

Published: June 19, 2019

Copyright $\odot 2019$ by author(s) and Scientific Research Publishing Inc. This work is licensed under the Creative Commons Attribution International License (CC BY 4.0).

http://creativecommons.org/licenses/by/4.0/

\begin{abstract}
Background: Human herpesvirus type 6 (HHV-6) has been shown to infect almost all children by 4 years of age. Primary infection causes an undifferentiated febrile illness, with approximately $30 \%$ of children exhibiting the classic clinical manifestations of roseola infantum. Objectives: The current study was carried out to explore the anti-HHV-6 IgG positivity rate as a marker of past infection among apparently healthy infants and to figure out the effect of certain infant and family characteristics on the infectivity rate. Materials and methods: This is a cross sectional study conducted in Diyala province during the period from August 2017-July 2018. A total of 180 apparently healthy infants were included, their ages ranged between $6-24$ months. They consist of 100 males with mean age \pm SD $15.05 \pm 6.42$ months and 80 females with mean age \pm SD $15.56 \pm 6.66$ months. Human privacy was respected by obtaining parental consent. Venous blood samples were collected aseptically from each participant. Sera were separated and tested for the anti-HHV6 IgG (Sunlong Biotech, China) by Enzyme Linked Immunosorbant assay (ELISA) technique. Statistical analysis was done using SPSS version 23 and $\mathrm{P}$ value $<$ 0.05 was considered significant. Results: The overall anti-HHV6 IgG positivity rate among apparently healthy infants was $43.9 \%$. The highest positivity rate was among the age group 19 - 24 months compared to other age groups, and the positivity rate was insignificantly higher among males compared to females $(44.0 \%$ vs. $43.8 \%, P=0.973)$. Furthermore, the positivity rate was insignificantly higher among infants on mixed feeding compared to other feeding categories $(55.3 \%, \mathrm{P}=0.083)$. The results also recognized that infants who had negative history of hospitalization had higher but insignificant positivity rate compared to their counterpart $(46.8 \%$ vs. $26.9 \%, P=0.065)$. Interestingly, a significantly higher anti-HHV6 IgG positivity rate was found among infants whom their families had current history of positive case $(62.2 \%)$ compared to families with negative history $(35.8 \%)$ or those with past history of
\end{abstract}


positive case $(50.0 \%, \mathrm{P}=0.006)$. Conclusion: About one half of apparently healthy infants aged up to two years of Diyala population have anti-HHV6 IgG antibodies and the presence of intrafamilial primary HHV-6 positive case is markedly associated with increased rate of anti-HHV6 IgG among siblings.

\section{Keywords}

Human Herpesvirus-6, Roseola Infantum, Diyala

\section{Introduction}

Human herpesvirus type 6 is a widespread beta-herpesvirus that was initially isolated in 1986 from patients with lymphoproliferative disorders [1], and initially characterized as a human T-lymphotropic virus [2]. It was officially classified as a member of the Herpesvirales order, Herpesviridae family, Beta-herpesvirinae subfamily and Roseolovirus genus, together with human herpesvirus 7 (HHV-7), a closely related herpesvirus discovered in 1990 [3]. HHV-6 infects a wide range of human cells in vitro, but it preferentially replicates in activated CD4+ T lymphocytes which are infected through their CD46 receptor [4]. The HHV-6 is ubiquitous being detected in all human populations around the world, as reviewed by (Stone et al., 2014) [5]. As a whole, HHV-6 infection is detected in more than $90 \%$ of adult populations in developed countries, although the seroprevalence may reveal significant differences according to geographic location, age, and sensitivity and specificity of serologic assays [6]. The HHV-6 infection is usually acquired very early in life, between 6 months and 2 years of age, following the loss of protective maternal antibodies [7]. Saliva is assumed to be the main vehicle for virus transmission, as supported by the frequent detection of HHV-6 in saliva and salivary glands [8]. Congenital infection following intrauterine transmission occurs in about $1 \%$ of children, and perinatal transmission has also been described [9]. The congenital infection is mainly linked with chromosomally integrated HHV-6 in mothers [10].

Primary HHV-6 infection has been found to be the cause of febrile illness, roseola infantum, in $10 \%$ to $45 \%$ of infants. A population-based study indicated that $40 \%$ of HHV- 6 infection occurs by age 12 months and $77 \%$ by age 24 months. It was more common in females and children with older siblings [11]. The peak incidence of the virus is in the spring and fall seasons [12] [13]. Three stages were recognized in the natural history of HHV-6 infection; the first is represented by acute primary infection in infants [14]. Detectable viremia is generally considered the hallmark of a systemic active infection and the whole blood is the most valuable specimen for detecting such viremia by real-time PCR [15] [16]. The second one occurs in healthy children and adults; the virus replicates in the salivary glands and is secreted in saliva without inducing any obvious pathology, remains latent at least in lymphocytes and monocytes, and 
persists in various tissues, possibly with a low-level replication [17]. The third stage occurs infrequently, typically in immunocompromised persons, and is linked to reactivation of virus from latency or reinfection [6] [18].

Anti-HHV-6 IgG as a marker of past or latent infection, different studies had yielded variable results. Among healthy Thai children aged 0 to 12 years, the anti-HHV6 IgG using an ELISA method was 88.10\% [19]. In Italian people, seropositivity of $83.7 \%, 92.6 \%$ and $63.6 \%$ were found in subjects aged 3 months - 6 years, 6 - 18 years and over 18 years respectively [20]. In Greece HHV-6 seropositivity among blood donors was $78.7 \%$ and the seroprevalence did not differ between males and females or among different decade age groups [21]. In another study on blood donors, 34\% were positive for IgG anti-HHV6 and with titers ranged from 1:40 to 1:160 [22]. It has been affirmed that Antibody responses after exanthem subitum were well correlated with clinical recovery from the disease [23]. This study was conducted to explore the anti-HHV-6 IgG positivity rate among apparently healthy infants and to figure out the effect of certain risk factors.

\section{Subjects and Methods}

This is a part of larger cross sectional study conducted in Diyala province during the period from August 2017-July 2018. A total of 180 apparently healthy (clinically they were free from any sign or symptoms) infants were included. They were collected from those attending for routine vaccination. Their ages ranged between 6 - 24 months. They consist of 100 males with mean age \pm SD $15.05 \pm$ 6.42 months and 80 females with mean age \pm SD $15.56 \pm 6.66$ months. Human privacy was respected by obtaining parental consent. Venous blood samples were collected aseptically from each participants. Sera were separated and tested for the anti-HHV-6 IgG (Sunlong Biotech, China) by Enzyme Linked Immunosorbant assay (ELISA) technique. Human privacy was respected by taken the parents consent. Furthermore, the study was permitted by the Ethical Commity in the College of Medicine-Diyala University. Statistical analysis was done using SPSS version 23 and P value $<0.05$ was considered significant. The frequency distributions for selected variables were done first. To measure the strength of association between 2 variables, such as the presence of certain explanatory variable (or risk factor) and a positive antibody test the odds ratio (OR) was used. The statistical significance of the measured OR is assessed by a special $\chi^{2}$ formula. The relative risk is the real measure of association between exposure to a certain factor and having positive antibody. The calculated OR is the best estimate for the real measure of relative risk (RR). The $95 \%$ confidence interval of an estimate gives an idea about the expected range the parameter in the target population with $95 \%$ confidence.

\section{Results}

The results found that the overall positivity rate of anti-HHV6 IgG among ap- 
parently healthy infants was $43.9 \%$. The distribution according to age groups found that the highest positivity rate was among children $19-24$ months (59.6\%), followed by the age group 13 - 18 months (53.3\%), and lastly among the age group 7 - 12 months (31.2\%). However, the difference was statistically insignificant (Table 1).

The anti-HHV6 positivity rate was slightly higher in males compared to females $(44.0 \%$ versus $43.8 \%)$ and the difference was statistically insignificant $(\mathrm{P}=$ 0.973), Table 2.

According to the type of feeding, the results found that mixed feeding $(55.3 \%)$ and bottle feeding $(42.7 \%)$ were insignificantly higher than the breast feeding (34.4\%), Table 3.

The anti-HHV6 IgG positivity rate among infants who had previous hospitalization was lower than that of children with negative history $(26.9 \%$ versus $46.8 \%)$, but the difference was failed to reach the levels of statistical significant, Table 4.

The results in Table 5 revealed that infants with currently positive family history had significantly higher anti-HHV6 IgG positivity rate compared to those children with negative history $(62.2 \%$ versus $35.8 \%, \mathrm{P}=0.006)$. On the other hand,

Table 1. Anti-HHV6 IgG positivity rate by age groups.

\begin{tabular}{ccccccc}
\hline Age (Ms) & Anti-IgG (\%) & Odd ratio & Inverse OR & 95\% CI & P value & PF \\
\hline $7-12$ & $29 / 93(31.2)$ & 0.46 & Reference & & & \\
$13-18$ & $16 / 30(53.3)$ & 0.86 & 1.17 & $(0.24-3.08)$ & $0.813[\mathrm{NS}]$ & 0.082 \\
$19-24$ & $34 / 57(59.6)$ & 0.59 & 1.71 & $(0.18-1.91)$ & $0.375[\mathrm{NS}]$ & 0.237 \\
Total & $79 / 180(43.9)$ & & & & & \\
\hline
\end{tabular}

Table 2. Anti-HHV6 IgG positivity rate by gender.

\begin{tabular}{ccccccc}
\hline Gender & Anti-IgG (\%) & Odd ratio & Inverse OR & $95 \%$ CI & P value & EF \\
\hline Female & $35 / 80(43.8)$ & 43.8 & Reference & & & \\
Male & $44 / 100(44.0)$ & 44 & 1.01 & $(0.56-1.83)$ & $0.973[\mathrm{NS}]$ & 0.004 \\
\hline
\end{tabular}

Table 3. Anti-HHV6 IgG positivity rate by type of feeding.

\begin{tabular}{cccccc}
\hline Type of Feeding & Anti-IgG (\%) & Odd ratio & $95 \%$ CI & P value & EF \\
\hline Breast & $11 / 32(34.4)$ & Ref & & & \\
Bottle & $47 / 110(42.7)$ & 1.42 & $(0.63-3.24)$ & $0.39[\mathrm{NS}]$ & 0.127 \\
Mixed & $21 / 38(55.3)$ & 2.36 & $(0.89-6.22)$ & $0.083[\mathrm{NS}]$ & 0.319 \\
\hline
\end{tabular}

Table 4. Anti-HHV6 IgG positivity rate according to previous hospitalization.

\begin{tabular}{cccccccc}
\hline Previous hospitalization & Anti-IgG (\%) & Odd ratio & Inverse OR & $95 \%$ CI & P value & PF \\
\hline Negative & $72 / 154(46.8)$ & Ref & & & & & \\
Positive & $7 / 26(26.9)$ & 0.42 & 2.38 & $(0.17-1.06)$ & $0.065[\mathrm{NS}]$ & 0.271 \\
\hline
\end{tabular}


Table 5. Anti-HHV6 IgG positivity rate according to family history.

\begin{tabular}{cccccc}
\hline Family history & Anti-IgG (\%) & Odd ratio & $95 \%$ CI & P value & EF \\
\hline Negative & $39 / 109(35.8)$ & Ref & & & \\
Positive past history & $17 / 34(50.0)$ & 1.79 & $(0.82-3.91)$ & $0.141[\mathrm{NS}]$ & 0.221 \\
Positive current history & $23 / 37(62.2)$ & 2.95 & $(1.37-6.37)$ & 0.006 & 0.411 \\
\hline
\end{tabular}

infants with positive past family history were also had higher anti-HHV6 IgG positivity rate compared to its negative counterpart, but the difference was failed to reach the levels of statistical significance $(50.0 \%$ versus $35.8 \%, \mathrm{P}=0.141$ ).

\section{Discussion}

Like other herpesviruses, HHV-6 causes a primary infection at early infancy life followed by latency and persistence of the virus in various body tissues with frequent reactivation under immunocompromised conditions [24]. During the second stage, latently infected children and adults clinically appear healthy while the virus replicates in the salivary glands and is secreted in saliva without inducing any obvious pathology, and persists possibly with a low-level replication [17]. As the virus persists inside the body, the infants or children are seroconverted from anti-HHV6 IgM to IgG antibodies which last for the life representing the serological marker of past infection [25] [26].

In the present study which was conducted on apparently healthy infants aged 6 - 24 months, the serum anti-HHV6 IgG was $43.9 \%$ as detected by ELISA technique. In this regard, different studies had yielded variable results. However, generally the result of the current study is low compared to other studies [19] [27]. This low anti-HHV 6 IgG positivity rate may be due to multi-factorials; for instance, it was found that infection with HHV 6 A variant provoked low anti-HHV 6 IgG titers that cannot be detected by serological procedures compared to HHV 6 B [23]. Furthermore, the IgG subclasses, as it was documented that anti-HHV6 IgG was restricted to IgG1, whereas anti-HHV-7 IgG subclasses included two groups, one restricted only to IgG1 and the other to IgG1 and IgG3 [28]. Additionally, the causative agent of primary infection of the clinically suspected roseola infantum cases may be other than HHV6 [5] [29]. It is worth to remember that clinically, the roseola infantum is closely similar to other five clinical conditions among infants and children and thus it is called the sixth disease [5] [12] [30]. Lastly, the sensitivity and specificity of the employed laboratory test may affect the study outcomes [27] [31].

Although it is insignificant, the results also found that the highest anti-HHV 6 IgG positivity rate was among those 19 - 24 months (59.6\%). Again in this regard, variable results had been obtained, but generally are consistent with the present results in that the anti-HHV 6 IgG positivity rate is gradually increased by infants or children age [20] [32]. Moreover, Ongradi et al. (1999) [23] reported that all infants had by the age of 1 month antibodies to HHV-6, which decreased with age to the lowest level at the age of 3 to 6 months and then in- 
creased and reached the maximum level by 1 to 2 years and the prevalence was almost stable after 3 years, affirming that antibody responses after exanthem subitum were well correlated with clinical recovery from the disease and the level of antibody was well correlated with indirect immunofluorescence assay and the neutralization test. Additionally, it was concluded that age is the important factor associated with HHV-6 infection, while sex, socioeconomic status, number of children in the family and child rearing place has no association [19].

Regarding the association of gender with the anti-HHV6 IgG positivity rate, the insignificant higher positivity rate among males obtained in this study is consistent with (Farshadmoghadam et al., 2014) [16]. On the contrary, Zerr et al., (2005) [11] found that the acquisition of HHV-6 was associated with female sex. Traditionally, in our community, parents, the older family members and relatives are more attracted to male infants, usually hold them and kiss them several times. Undoubtedly, these unhealthy practices are efficiently responsible for the transmission of HHV 6 to infants through the saliva or other oral fluids [8] [33].

A fascinating finding was that the anti-HHV 6 IgG positivity rate was significantly higher among family siblings who had a current positive case. These results is seems logic and consistent with most previous studies [34] [35]. It has been documented that the risk of HHV 6 infection increase by the number of siblings and the frequency that the child received parental saliva when being kissed [8]. Certainly it is well documented that the HHV 6 is intensively found in saliva and oral fluids, even in healthy population [33]. Probably the most prominent limitations of this study were the limited age group included and limited number of participants due to expensiveness of laboratory material as this study was personally funded.

\section{Conclusion}

In conclusion, about one-half of apparently healthy infants up to two years of Diyala population have anti-HHV6 IgG antibodies and the presence of intrafamilial primary HHV-6 positive case is markedly associated with the increased rate of anti-HHV6 IgG among siblings.

\section{Conflicts of Interest}

The authors declare no conflicts of interest regarding the publication of this paper.

\section{References}

[1] Salahuddin, S.Z., Ablashi, D.V., Markham, P.D., Josephs, S.F., Sturzenegger, S. Kaplan, M., Halligan, G., Biberfeld, P., Wong-Staal, F. and Kramarsky, B. (1986) Isolation of a New Virus, HBLV, in Patients with Lymphoproliferative Disorders. Science, 234, 596-601. https://doi.org/10.1126/science.2876520

[2] Ablashi, D.V., Salahuddin, S.Z., Josephs, S.F., Imam, F., Lusso, P. and Gallo, R.C. (1987) HBLV (or HHV-6) in Human Cell Lines. Nature, 329, 207. 
https://doi.org/10.1038/329207a0

[3] Frenkel, N., Schirmer, E.C., Wyatt, L.S., Katsafanas, G., Roffman, E., Danovich, R.M. and June, C.H. (1990) Isolation of a New Herpesvirus from Human CD4+ T Cells. Proceedings of the National Academy of Sciences of the United States of America, 87, 748-752. https://doi.org/10.1073/pnas.87.2.748

[4] Flamand, L., Komaroff, A.L., Arbuckle, J.H., Medveczky, P.G. and Ablashi, D.V. (2010) Human Herpesvirus-6-Basic Biology, Diagnostic Testing, and Antiviral Efficacy. Journal of Medical Virology, 82, 1560-1568. https://doi.org/10.1002/jmv.21839

[5] Stone, R.C., Micali, G.A. and Schwartz, R.A. (2014) Roseola Infantum and Its Causal Human Herpesviruses. International Journal of Dermatology, 53, 397-403. https://doi.org/10.1111/ijd.12310

[6] Ward, K.N. (2005) The Natural History and Laboratory Diagnosis of Human Herpesviruses- 6 and -7 Infections in the Immunocompetent. Journal of Clinical Virology, 32, 183-193. https://doi.org/10.1016/j.jcv.2004.11.008

[7] Becerra, A., Gibson, L., Stern, L.J. and Calvo-Calle, J.M. (2014) Immune Response to HHV-6 and Implications for Immunotherapy. Current Opinion in Virology, 9, 154-161. https://doi.org/10.1016/j.coviro.2014.10.001

[8] Rhoads, M.P., Magaret, A.S. and Zerr, D.M. (2007) Family Saliva Sharing Behaviors and Age of Human Herpesvirus-6B Infection. Journal of Infection, 54, 623-626. https://doi.org/10.1016/j.jinf.2006.11.012

[9] Hall, C.B., Caserta, M.T., Schnabel, K.C., McDermott, M.P., Lofthus, G.K., Carnahan, J.A., Gilbert, L.M. and Dewhurst, S. (2006) Characteristics and Acquisition of Human Herpesvirus (HHV) 7 Infections in Relation to Infection with HHV-6. The Journal of Infectious Diseases, 193, 1063-1069. https://doi.org/10.1086/503434

[10] Pantry, S.N. and Medveczky, P.G. (2017) Latency, Integration, and Reactivation of Human Herpesvirus-6. Viruses, 9, pii: E194. https://doi.org/10.3390/v9070194

[11] Zerr, D.M., Meier, A.S., Selke, S.S., Frenkel, L.M., Huang, M.L., Wald, A., Rhoads, M.P., Nguy, L., Bornemann, R., Morrow, R.A. and Corey, L. (2005) A Population-Based Study of Primary Human Herpesvirus 6 Infection. The New England Journal of Medicine, 352, 768-776. https://doi.org/10.1056/NEJMoa042207

[12] Tesini, B.L., Epstein, L.G. and Caserta, M.T. (2014) Clinical Impact of Primary Infection with Roseoloviruses. Current Opinion in Virology, 9, 91-96. https://doi.org/10.1016/j.coviro.2014.09.013

[13] Agut, H., Bonnafous, P. and Gautheret-Dejean, A. (2015) Laboratory and Clinical Aspects of Human Herpesvirus 6 Infections. Clinical Microbiology Reviews, 28, 313-335. https://doi.org/10.1128/CMR.00122-14

[14] Arnez, M., Avsie-Zupanc, T., Ursic, T. and Petrovec, M. (2016) Human Herpesvirus 6 Infection Presenting as an Acute Febrile Illness Associated with Thrombocytopenia and Leukopenia. Case Reports in Pediatrics, 2016, Article ID: 2483183.

https://doi.org/10.1155/2016/2483183

[15] Caserta, M.T., Hall, C.B., Schnabel, K., Lofthus, G., Marino, A., Shelley, L., Yoo, C., Carnahan, J., Anderson, L. and Wang, H. (2010) Diagnostic Assays for Active Infection with Human Herpesvirus 6 (HHV-6). Journal of Clinical Virology, 48, 55-57. https://doi.org/10.1016/j.jcv.2010.02.007

[16] Farshadmoghadam, H., Pourakbari, B., Mahmoudi, S., Sadeghi, R.H. and Mamishi, S. (2014) Human Herpesvirus 6 Infection in Febrile Children: Frequency in an Iranian Referral Hospital. British Journal of Biomedical Science, 71, 108-110. 
https://doi.org/10.1080/09674845.2014.11669974

[17] Caserta, M.T., McDermott, M.P., Dewhurst, S., Schnabel, K., Carnahan, J.A., Gilbert, L., Lathan, G., Lofthus, G.K. and Hall, C.B. (2004) Human Herpesvirus 6 (HHV6) DNA Persistence and Reactivation in Healthy Children. The Journal of Pediatrics, 145, 478-484. https://doi.org/10.1016/j.jpeds.2004.06.016

[18] Dockrell, D.H. (2003) Human Herpesvirus 6: Molecular Biology and Clinical Features. Journal of Medical Microbiology, 52, 5-18. https://doi.org/10.1099/jmm.0.05074-0

[19] Bhattarakosol, P., Pancharoen, C., Mekmullica, J. and Bhattarakosol, P. (2001) Seroprevalence of Anti-Human Herpes Virus-6 IgG Antibody in Children of Bangkok, Thailand. The Southeast Asian Journal of Tropical Medicine and Public Health, 32, 143-147.

[20] Cermelli, C., Moroni, A., Pietrosemoli, P., Pecorari, M. and Portolani, M. (1992) IgG Antibodies to Human Herpesvirus-6 (HHV-6) in Italian People. Microbiologica, 15, 57-63.

[21] Politou, M., Koutras, D., Kaparos, G., Valsami, S., Pittaras, T., Logothetis, E., Panayiotakopoulos, G. and Kouskouni, E. (2014) Seroprevalence of HHV-6 and HHV-8 among Blood Donors in Greece. Virology Journal, 11, 153. https://doi.org/10.1186/1743-422X-11-153

[22] Cuende, J.I., Ruiz, J., Civeira, M.P. and Prieto, J. (1994) High Prevalence of HHV-6 DNA in Peripheral Blood Mononuclear Cells of Healthy Individuals Detected by Nested-PCR. Journal of Medical Virology, 43, 115-118. https://doi.org/10.1002/jmv.1890430203

[23] Ongradi, J., Csiszar, A., Marodi, C.L., Solyom, J., Horvath, A. and Menezes, J. (1999) Presence of Antibodies to Human Herpesvirus Type 6 and 7 in Hungarian Children. Orvosi Hetilap, 140, 935-940.

[24] Agut, H., Bonnafous, P. and Gautheret-Dejean, A. (2017) Update on Infections with Human Herpesviruses 6A, 6B, and 7. Médecine et Maladies Infectieuses, 47, 83-91. https://doi.org/10.1016/j.medmal.2016.09.004

[25] Suga, S., Yoshikawa, T., Kajita, Y., Ozaki, T. and Asano, Y. (1998) Prospective Study of Persistence and Excretion of Human Herpesvirus-6 in Patients with Exanthem Subitum and Their Parents. Pediatrics, 102, 900-904.

https://doi.org/10.1542/peds.102.4.900

[26] De Bolle, L., Naesens, L. and De Clercq, E. (2005) Update on Human Herpesvirus 6 Biology, Clinical Features, and Therapy. Clinical Microbiology Reviews, 18, 217-245. https://doi.org/10.1128/CMR.18.1.217-245.2005

[27] Ward, K.N., Couto Parada, X., Passas, J. and Thiruchelvam, A.D. (2002) Evaluation of the Specificity and Sensitivity of Indirect Immunofluorescence Tests for IgG to Human Herpesviruses-6 and -7. Journal of Virological Methods, 106, 107-113. https://doi.org/10.1016/S0166-0934(02)00141-6

[28] Biganzoli, P., Ferreyra, L., Sicilia, P., Carabajal, C., Frattari, S., Littvik, A., Nates, S. and Pavan, J. (2010) IgG Subclasses and DNA Detection of HHV-6 and HHV-7 in Healthy Individuals. Journal of Medical Virology, 82, 1679-1683. https://doi.org/10.1002/jmv.21880

[29] Davidkin, I., Valle, M., Peltola, H., Hovi, T., Paunio, M., Roivainen, M., Linnavuori, K., Jokinen, S. and Leinikki, P. (1998) Etiology of Measles- and Rubella-Like Illnesses in Measles, Mumps, and Rubella-Vaccinated Children. The Journal of Infectious Diseases, 178, 1567-1570. https://doi.org/10.1086/314513 
[30] Helwig, H. and Cremer, H. (2011) Exanthema Subitum-3 Day Fever-HHV 6 Infection-Roseola Infantum-6th Disease. Kinderkrankenschwester, 30, 164-165.

[31] Ward, K.N., Gray, J.J., Fotheringham, M.W. and Sheldon, M.J. (1993) IgG Antibodies to Human Herpesvirus-6 in Young Children: Changes in Avidity of Antibody Correlate with Time after Infection. Journal of Medical Virology, 39, 131-138. https://doi.org/10.1002/jmv.1890390209

[32] Asano, Y., Yoshikawa, T., Suga, S., Yazak, T., Ozaki, T., Saito, Y., Hatano, Y. and Takahashi, M. (1990) Enzyme-Linked Immunosorbent Assay for Detection of IgG Antibody to Human Herpesvirus 6. Journal of Medical Virology, 32, 119-123. https://doi.org/10.1002/jmv.1890320209

[33] Pereira, C.M., Gasparetto, P., Correa, M.E., Costa, F.F., de Almeida, O.P. and Barjas-Castro, M.L. (2004) Human Herpesvirus 6 in Oral Fluids from Healthy Individuals. Archives of Oral Biology, 49, 1043-1046. https://doi.org/10.1016/j.archoralbio.2004.06.002

[34] Lanphear, B.P., Hall, C.B., Black, J. and Auinger, P. (1998) Risk Factors for the Early Acquisition of Human Herpesvirus 6 and Human Herpesvirus 7 Infections in Children. The Pediatric Infectious Disease Journal, 17, 792-795.

https://doi.org/10.1097/00006454-199809000-00008

[35] Vianna, R.A., de Oliveira, S.A., Camacho, L.A., Knowles, W., Brown, D., Pereira, A.C., Velarde, L.G. and Siqueira, M.M. (2008) Role of Human Herpesvirus 6 Infection in Young Brazilian Children with Rash Illnesses. The Pediatric Infectious Disease Journal, 27, 533-537. https://doi.org/10.1097/INF.0b013e3181673c50 